\title{
Creating value through autonomous shipping: an ecosystem perspective
}

\author{
Anastasia Tsvetkova ${ }^{1} \cdot$ Magnus Hellström $^{1,2}$
}

Accepted: 22 December 2021 / Published online: 26 January 2022

(C) The Author(s) 2022

\begin{abstract}
The expected benefits of Maritime Autonomous Surface Ships (MASS) include increased safety, reduced costs and increased earning potential due to operational efficiencies and reduction in vessel manning. However, autonomous shipping enabled by such ships bears a greater potential than just replacing humans with machines. Rather, MASS can play a role in transforming supply and logistics chains. The value creation potential of these ships depends on the degree to which they disrupt logistics. Our aim here is to clarify how MASS create value and for whom, as well as how different actors in the maritime logistics ecosystem are able to monetize or otherwise benefit from the innovation. Based on interviews with experts in maritime logistics and autonomous technology, and a desktop study of the opinions of the leaders in maritime innovation, we analyse the different facets of value creation by MASS. We distinguish between the two key sources of value - onboard crew reduction and increased ship intelligence and their effects (cost reductions, earning potential, increased safety and system value) - and explicate for which actors in the ecosystem the value is created. We identify the key changes in the maritime logistics ecosystem, which concern the changing roles of technology providers, shipowners and operators, and we highlight the need for developing complementary infrastructure and activities in the ecosystem.
\end{abstract}

Keywords MASS · Autonomous ships · Supply chain management · Logistics · Value creation $\cdot$ Business models $\cdot$ Business ecosystem

Anastasia Tsvetkova

anastasia.tsvetkova@abo.fi

1 Laboratory of Industrial Management, Faculty of Science and Engineering, Åbo Akademi University, Turku, Finland

2 Department of Working Life and Innovation, School of Business and Law at University of Agder, Grimstad, Norway 


\section{Introduction}

Automation and, more recently, digitalization have been increasingly adopted in maritime transportation (Heilig and Voß 2017; Inkinen et al. 2019; Baldauf et al. 2018). Yet, the introduction of Maritime Autonomous Surface Ships (MASS) into commercial shipping remains a challenging and uncertain concept. Some benefits of MASS are obvious and well understood, such as reduced costs due to rendering all or part of the manning redundant, and so are some barriers, such as certain legal issues of autonomous shipping (Ringbom 2019) and the lack of a credible business case (Wright 2020). However, the introduction of MASS is a system innovation that will have considerable impact on supply and logistics chains beyond that of cost reduction and individual business cases. Such a system innovation is also affected by barriers pertinent to the question of how maritime logistics is currently organized, as this may change the entire institutional structure of the shipping business (Tsvetkova et al. 2021b; Munim 2019; Ghaderi 2020). For example, the ultimate users of logistics services - shippers - can gain an unprecedented control on how their goods are transported in a fully automated and transparent supply chain, which relies on MASS, automated ports and other enabling innovations.

A particular problem with MASS seems to be that the business actors investing in the technology may not be the ones to benefit from it. In particular, the shipowners who usually undertake the ship investment benefit only partly from the expensive technology installed on MASS, while the benefits from operating such ships, such as fuel savings or increased cargo-carrying capacity, will be enjoyed by the ship operator. The higher value of MASS can theoretically be reflected in charter rates, thus allowing the shipowner to capture the value. However, in practice, it is yet unclear how much of the ship investment costs can be passed on to the ship operator. To provide another example, the value of transporting cargo using a fleet of MASS, and consequent opportunities for optimizing logistics chains, is created for shippers, who are not part of the investment decision unless it is a vertically integrated logistics chain. Hence, to understand and facilitate the transition and overcome the barriers, we argue that there is a need to take a business ecosystem view (Moore 1996; Adner 2017) on autonomous shipping, which allows one to consider the mechanisms for both value creation and capture of a group of interconnected firms (Talmar et al. 2018). A business ecosystem view allows reassessment of the structure of an incumbent industry when new value propositions make formerly disconnected sectors (e.g. the maritime and the information technology industry) intersect (Adner 2017). It also, by definition, resonates well with the idea of unleashing system benefits of autonomous shipping, which requires the alignment of the business models of incumbent actors and new entrants (Snihur et al. 2018). Such a study would complement earlier studies that have focused on the implications of embedding MASS in as-is supply chains (Kretschmann et al. 2017) and discuss the implications of the changing roles of the different actors in the forming ecosystem around autonomous shipping. 
Therefore, we pose the following research question to guide our study: How can various actors in the logistics business ecosystem create and capture value through MASS, and how does the logistics business ecosystem have to change for this to happen? Thus, we analyse the value creation potential of MASS according to the source of value (does it stem from reducing the crew onboard or increasing ship intelligence, or both?), and analyse which actors in the supply chain would receive this value. Based on this analysis, and by applying an ecosystem perspective, we draw conclusions on what the main implications are for current logistics and supply chains, and how they need to change as MASS are increasingly introduced.

The remainder of the study is organized as follows: In the next section, we provide an overview of state-of-the art of MASS and of the literature on value creation in business ecosystems, while also further justifying the ecosystem view. We then briefly describe the research setting and the qualitative method which we have applied. We present our findings in terms of the different facets of value of MASS which we identified, and in terms of the challenges and required changes for ensuring value capture among all required parties and for enabling complementarities. We conclude by summarizing our main findings and by advising future research areas.

\section{Literature review}

\subsection{The benefits of MASS and their impact on maritime logistics ecosystem}

MASS can be seen as part of a broader digitalization trend, capable of changing the conduct of business (Urciuoli and Hintsa 2020; Porter and Heppelmann 2015). MASS have been defined as vessels that "to a varying degree, can operate independently of human interaction" (IMO 2018). Together with this definition, the International Maritime Organization (IMO) has defined four degrees of autonomy, which include the following: (1) crewed ships with automated processes and decision support; (2) remotely controlled ships with seafarers on board; (3) remotely controlled ships without seafarers on board; (4) fully autonomous ships. Since vessels with any degree of autonomy can be considered MASS, and MASS could be operating at one or more degrees of autonomy for the duration of a single voyage, it is useful to separate two key aspects of the development towards autonomous shipping: level of onboard manning and level of autonomy, i.e. independence from human operation, as depicted in Fig. 1 (Ringbom 2019). To provide an example, a remotely controlled ship operating at the third degree of autonomy is not, strictly speaking, operating autonomously if a human navigator is making decisions from a shore-based control centre (SCC). Both aspects exist to a varying degree, when only some functions on a MASS can be operated remotely or autonomously at different points of the voyage.

There are a number of benefits of MASS that are discussed in the literature on the future of autonomous shipping. These include reduced operational, voyage and crew costs; increased safety of operations; and earning potential from new vessel designs (Meadow et al. 2018; Kim et al. 2020; Ghaderi 2019; Munim 2019). The potential to 


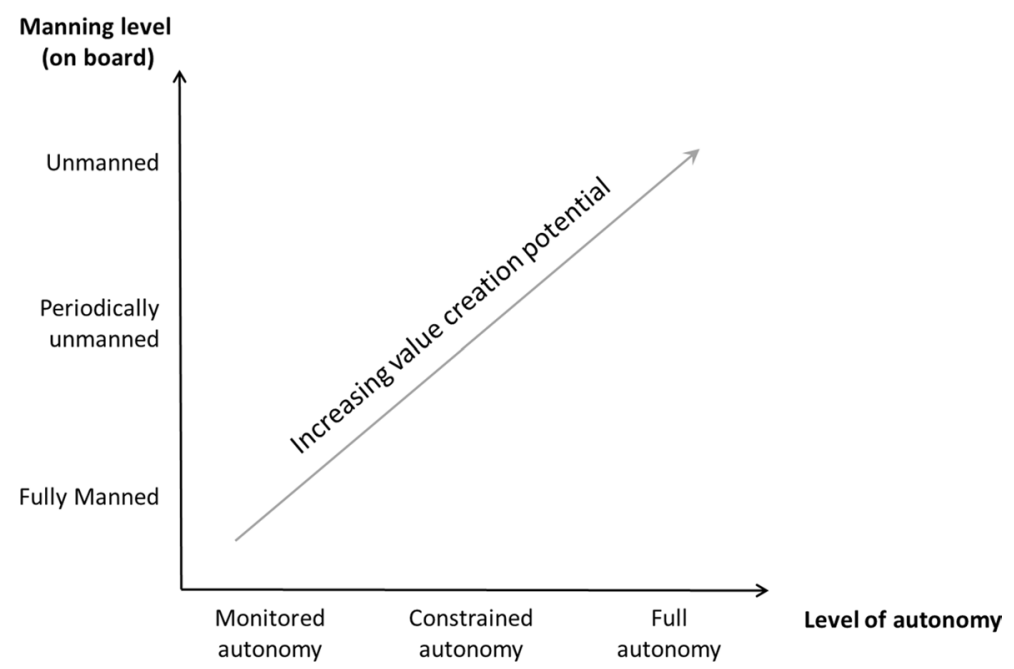

Fig. 1 Separation of aspects of automation. Adapted from Ringbom (2019)

integrate MASS in the Internet of Things (IoT) within logistics and supply chains is yet another foundation of potential benefits (Ghaderi 2019).

While earlier studies have quantified the benefits of MASS (Kretschmann et al. 2017), these calculations are based on assumptions, such that MASS operate and generate revenue following the same principles as conventional ships. While at early stages MASS will indeed compete with conventional ships, the introduction of MASS provides opportunities for novel business models which will be based on different value creation and capture logics, as discussed below. Moreover, given the fragmented structure of maritime logistics (Gustafsson et al. 2015), it is not apparent what kind of value will be created and for whom, as MASS are increasingly introduced. This warrants an ecosystem perspective on the ways MASS can create value within existing, incumbent logistics business ecosystems. The incumbent actors include, among others, ship systems providers (technology providers), shipbuilders (shipyards), shipowners, ship operators, freight forwarders, shipbrokers and shippers (owners or suppliers of commodities that are shipped).

\subsection{Value creation in ecosystems}

Given the fragmented sea logistics value chain, studying value creation in it makes the business ecosystem view relevant. The term was originally coined by Moore (1996), who described a business ecosystem as an economic community of interacting organizations and individuals producing goods and services of value to customers. The concept has received increasing attention in the general management and strategy literature ever since, and today it is commonly agreed that the defining feature of business ecosystems is value co-creation (often based on technological and activity complementarities) and co-evolution of interdependent organizations (Adner 2017; Jacobides et al. 2018). A widely cited definition was put forward by 
Adner (2017), who defined a business ecosystem as "the alignment structure of the multilateral set of partners that need to interact in order for a focal value proposition to materialize" (Adner 2017, p. 40). Adner (2017) contrasts this activity-centric, ecosystem-as-structure view with an actor-centric, ecosystem-as-affiliation view, which emphasizes the network characteristics of ecosystems. Due to our explicit focus on value creation, we adhere to the ecosystem-as-structure view.

Drawing on the ecosystem-as-structure view and definition, we stress two key characteristics of business ecosystems. Firstly, there is a system-level business goal, expressed through the focal value proposition (Gulati et al. 2012). Secondly, achieving the system-level goal builds on a system of interdependent firms whose performance depends on the actions of their collaborators (Adner and Kapoor 2010; Moore 1996). To our knowledge, the business ecosystem perspective has not been widely applied in the supply chain, logistics or transportation management literature, especially in the context of maritime logistics (for some exceptions, see Eriksson et al. 2019; Urciuoli and Hintsa 2020). Stakeholder analysis, and in particular research on port stakeholders (see e.g. Lam et al. 2013; Denktas-Sakar and Karatas-Cetin 2012), comes close to the study of business ecosystems in addressing the interdependency of multiple actors, which might belong to different industrial sectors. Ports can thus be perceived as local business ecosystems, the success of which depends on the collaboration and coordination among the various port stakeholders.

As MASS and autonomous shipping as such are a system innovation that is likely to introduce systemic changes to the shipping industry, the idea of a system-level goal apparently becomes relevant. MASS are not like an incremental innovation that can be easily adopted within existing supply chain structures. Rather, MASS are to be seen as a radical innovation that is likely to disrupt at least parts of the industry and its institutionalized structure of value creation, including a redefinition of logistics and supply chains. It is also obvious that the value propositions of many actors are needed to deliver the promised "system" value of autonomous solutions (Adner 2017; Tsvetkova et al. 2017). This leads us to a third characteristic of business ecosystems that is central to our study, namely that of complementarity (Zott and Amit 2010; Jacobides et al. 2018). That is, value created in business ecosystems requires the input from many actors, and for an ecosystem actor to deliver value of their product or service, it is necessary to create a specific alignment with several other ecosystem actors, whose value propositions are complementary. In the case of MASS, a few complementary value propositions are necessary to deliver the value of MASS, such as highly automated ports that can accommodate MASS, SCCs and their operations, and continuous and reliable connectivity at sea.

The business ecosystems metaphor also captures the fact that industries and their value creation architectures are constantly changing. Although not a necessary condition for making the ecosystem perspective relevant, the ongoing digitalization of the maritime business makes it particularly apt as an analytical lens. Digitalization tends to evoke changes in institutionalized ecosystems, as we have witnessed from some famous consumer market cases, such as Uber and Airbnb, over the past two decades. So-called digital ecosystems also appear to have significant potential for maritime transportation (Urciuoli and Hintsa 2020). 
Conceptually, the business ecosystem term comes close to the concepts of a supply and value chain, and of business network. Certain efforts have been made to distinguish these terms from each other. Adner (2017) points to the fact that both the conceptions of supply and value chains are constructs that, although involving multiple parties, often treat relationships as dyadic. Hence, these concepts seem to revolve around the issue of managing and securing supply, rather than on shifting position (Adner 2017). The ecosystem concept has been used in some operations and supply chain management journals, where the concept seems to be given a broader meaning than that of a supply chain. For example, Viswanadham and Samvedi (2013) describe a business ecosystem as a network of companies that are directly and indirectly parts of the supply chain. They also include governmental political actors as part of the ecosystem (although these admittedly are not necessarily part of the value creation structure). Liu et al. (2019), in their turn, use a business ecosystem in a more strategic sense and argue for the importance of shared value.

The business ecosystem concept also comes close to the business model concept that has been used to analyse the commercial application of MASS (Munim 2019). A common definition of a business model is that it delineates how value is created, delivered and captured in a firm (see e.g. Amit and Zott 2001; Zott and Amit 2010; Teece 2010; Osterwalder and Pigneur 2010). Such a view obviously is firm-centric. A business model is, however, a systemic concept in that it connects elements in the firm and relationships between firms into a holistic view (Zott et al. 2011). Hence, we operationalize business ecosystems as business model dependencies (Hellström et al. 2015; Talmar et al. 2018). Such an approach is likely to facilitate a systemic understanding of value creation and capture, as opposed to looking at MASS as isolated new products. To summarize, we will focus on the potential for value creation through complementarities and the changing roles of ecosystem actors - both incumbent, such as logistics operators, and new entrants, such as technology providers - and the subsequent redefinition of the value creation and value capture structure in the maritime logistics business ecosystem.

\section{Research setting and methodology}

Since the ecosystem around MASS is still in its early formation, it is challenging to study how exactly this innovation will create value for each ecosystem actor. To approach this issue, we studied opinions and indications of which changes are necessary and likely to happen through in-depth interviews with experts involved in the sea logistics ecosystem and through the study of secondary sources. When choosing the interviewees for this study, we attempted to obtain a multi-actor perspective - for example, by interviewing both providers of autonomous capability for ships and incumbent actors in the ecosystem. As a result, we interviewed industry experts, consultants and academics in business, regulation, technology, and ship navigation and operations, as well as naval school educators and trainers (Table 1).

Then, through desktop analysis of secondary sources, including scientific literature, news and trade magazines, and industry reports, we collected information on the prospects of widely implementing MASS. We focused on organizations listed as 


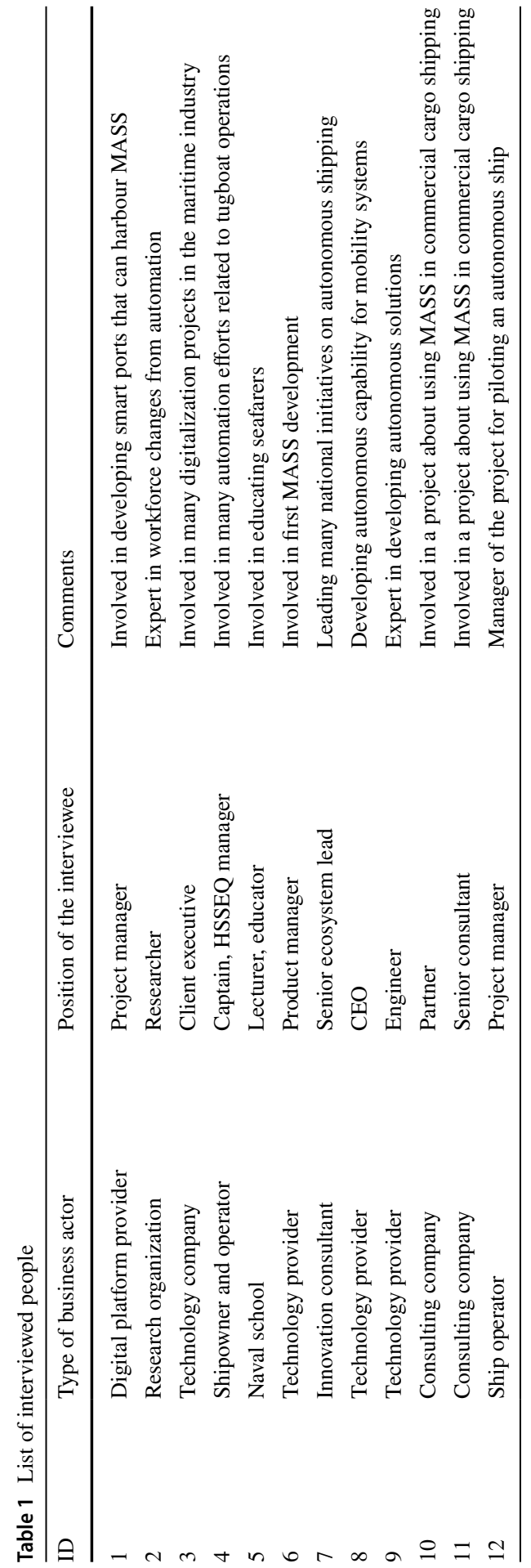


Table 2 Secondary data sources

\begin{tabular}{lcl}
\hline Type of secondary source & $\begin{array}{l}\text { Num- } \\
\text { ber of } \\
\text { sources }\end{array}$ & Examples \\
\hline News item on web portals & 12 & $\begin{array}{l}\text { maritime-executive.com, company webpages } \\
\text { Webinar on smart shipping, podcasts by maritime educational } \\
\text { institutions }\end{array}$ \\
$\begin{array}{l}\text { Podcasts, webinars, blogs } \\
\begin{array}{l}\text { Reports, research and trade } \\
\text { magazine articles and } \\
\text { papers }\end{array}\end{array}$ & 6 & $\begin{array}{l}\text { Technical articles, reports from research projects, consultancy } \\
\text { reports }\end{array}$ \\
$\begin{array}{l}\text { Laws, regulations, guidelines } \\
\text { International Convention on Standards of Training, Certifica- } \\
\text { tion and Watchkeeping, Regulation VIII/2(2)(1) }\end{array}$ \\
\hline
\end{tabular}

leaders in maritime technology, such as ABB Marine and Ports, DNV GL, Kongsberg, Rolls-Royce Marine, and Wärtsilä (Lloyd's List 2017). See Table 2 for more details on secondary data used in this study.

We analysed the data obtained through the interviews to elicit the patterns of value creation that can be enabled by MASS. We were partly guided by the categories that emerged in previous research on the benefits of MASS (Wright 2020; Kretschmann et al. 2017; Meadow et al. 2018; Kim et al. 2020; Ghaderi 2019; Munim 2019), but we also induced several categories from the data. Thus, we did content analysis with deductive category application and further inductive category development (Mayring 2004). To reach reliable category development, two researchers independently analysed detailed interview notes, identifying statements that related to the value of MASS. Then, we compared notes and agreed on the categories by merging some of them and revisiting the original texts in case of dissimilarities in identified value of MASS. Finally, we grouped the identified instances of value according to the source of value and into several categories that emerged during the analysis, as discussed in the next section. We used the secondary data to triangulate our findings (Cohen et al. 2017) and ensure that we grasp the different perspectives of various ecosystem actors.

\section{Results and discussion}

In this section, we make a detailed analysis of the potential of MASS to create value for the different ecosystem actors. This analysis is based on the data obtained through the in-depth interviews discussed in the previous section, as well as on desktop study of online materials where the benefits of MASS are discussed. The categorization is supported by the review of the literature related to the future of MASS, which was introduced earlier in the study.

As discussed earlier in Sect. 2, the operation of MASS can imply different levels of manning onboard, and vessel autonomy, due to the following possibilities: (1) operating vessels remotely from a SCC; (2) allowing vessels to perform only certain functions autonomously; (3) alternating between performing certain functions such 
as navigation by the crew or by MASS during the same voyage. Since autonomy in this case implies vessel operation independent of human interaction to a varying degree (IMO 2018), we see the need to distinguish the different sources of value creation through MASS and to study how benefits ascribed to MASS can be realized, depending on the levels of onboard manning and actual autonomy. Thus, we distinguish between the following two sources of value creation through MASS: onboard crew reduction and increased ship intelligence. By 'ship intelligence' we mean the array of automation and digitalization solutions implemented on vessels that enable autonomous operations, i.e. operations without human intervention. These include, for example, vessel situational awareness, voyage optimization or cargo monitoring systems. The term was coined by one of the leaders in MASS development, RollsRoyce, ${ }^{1}$ and brought up by Kretschmann et al. (2017) as a source of benefit from autonomous vessels which goes beyond benefits that stem from unmanned vessels. It is important to distinguish between these two sources of value creation because benefits ascribed to MASS, such as the potential for drastically new ship designs, can concern only fully unmanned ships. On the other hand, benefits arising from the availability of new types of data and opportunities for optimizing vessel operations due to digital solutions onboard stem from increasing ship intelligence, which is necessary for autonomous operations but could as well be realized on conventional fully manned ships.

Further, we distinguish among the different categories of value created by MASS. The interview data, as well as the literature review, pointed to several key topics regarding how value can be created by MASS: through cost reductions and operational efficiencies; through increased safety; through increased or novel earning potential; and through enabling system value, which we discuss in detail below. In Table 3, we present the different facets of value creation by MASS, organized by the sources of value and the categories of value. We discuss these categories in more detail in the table.

\subsection{Cost reductions and operational efficiencies}

The most obvious and commonly mentioned benefit of MASS is the potential to drastically decrease crew costs depending on how many crew members or maintenance personnel will be left on board, and how many people are required for operating the vessels from a SCC. Currently, crew salaries can account for up to $45 \%$ of total operating costs of a Panamax bulk carrier (Kretschmann et al. 2017), and reduction in crew costs would constitute tangible cost savings for ship operators. MASS can also address the challenge of attracting and training seafarers that ship operators have been recently facing (Björkroth 2020; Ghaderi 2020; Nguyen et al. 2014).

Removing the crew from vessels has also implications for ship design and operations, which, in their turn, can enable other efficiencies. As one interviewee

\footnotetext{
1 See e.g. https://www.rolls-royce.com/ /media/Files/R/Rolls-Royce/documents/customers/marine/RRShip-Intel-Broch-Oct2018.pdf.
} 


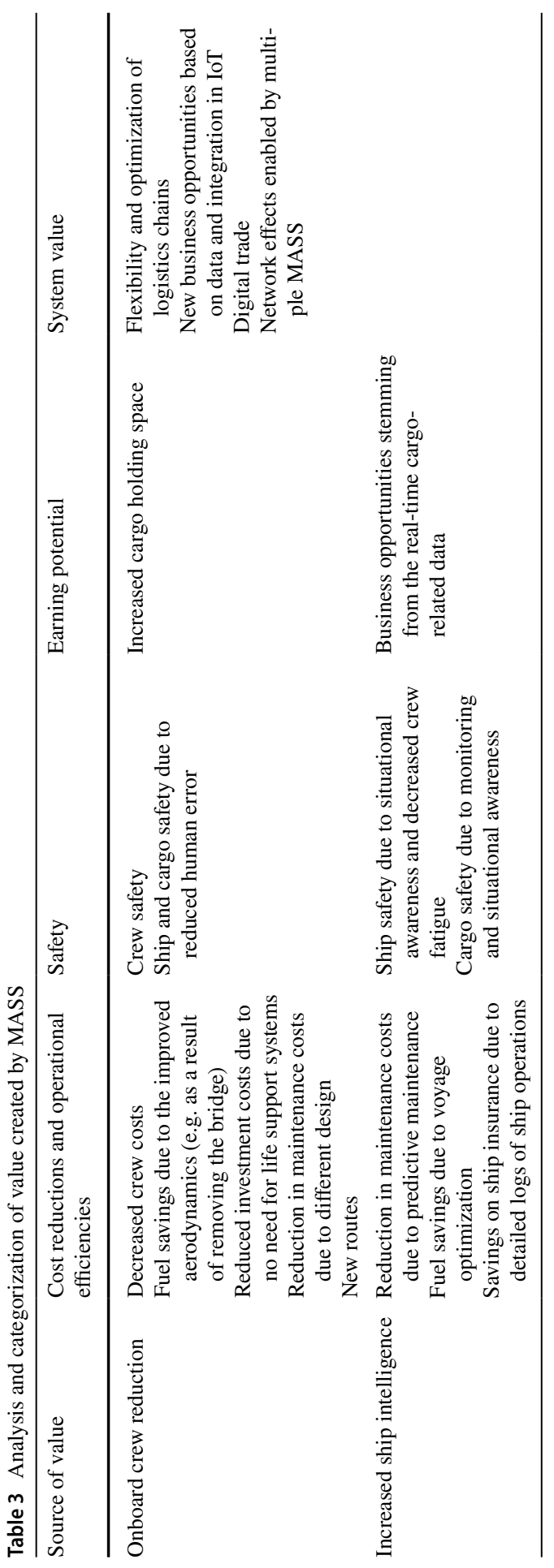

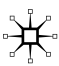


mentioned, the operational decisions during the voyage, regarding the speed or tilt of the vessel, will be different if not accounting for people on board, and the principles of designing ships will change, too. Fully unmanned vessels do not require crew quarters and life support systems, thereby reducing investment costs and enlarging cargo space. Naturally, there will be increased investments in ship intelligence solutions, such as situational awareness and collision detection systems, and other technological tools required for a vessel to be fully unmanned and autonomous. According to another interviewee, new designs are possible with improved airand hydrodynamics; ships can be lighter and require less ballast water. As a result, MASS can be more fuel-efficient compared with conventional ships, both due to improved design (Kretschmann et al. 2017) and optimal sailing speed profiles enabled by solutions like voyage optimization. Also, since the absence of crew costs on board reduces operational costs at sea, slow steaming becomes more viable, leading to even greater fuel savings (Hogg and Ghosh 2016). According to Rolls-Royce (Mooney 2015), MASS can achieve a 20\% reduction in fuel costs. Additionally, removal of crew from the vessels can uncover opportunities for transporting cargo using new routes, such as through the Arctic region (Munim et al. 2021).

The maintenance of MASS will also be affected by the removal of crew-related systems on the ship. However, increased automation will ultimately increase the complexity of the vessels. At the same time, ship intelligence can enable preventive and even predictive maintenance (Tsvetkova et al. 2021a; Lambert et al. 2019), which can reduce maintenance costs in the long term. Another important benefit stemming from increased ship intelligence is the increased transparency of ship operations due to the bigger volumes of recorded data on vessel equipment operation, cargo condition throughout the voyage and detailed logs of the surroundings. The use of these data, if made available to insurers, for investigating the causes of accidents or damages to the vessels and cargo, can ultimately lead to decreased ship and cargo insurance and help mitigate risks in sea transportation (Urciuoli and Hintsa 2020). However, as several interviewees explained to us, current ship and cargo insurance policies need to change in order to benefit from such transparency, which requires changes in how different actors communicate and settle disputes in case of accidents. As an interviewee from a ship operating company explained, often, insurance companies prefer to ensure a good relationship with their client rather than argue about every single claim over cargo damages. Following this, new interfaces will need to be established between insurance companies and such actors as ship systems providers, where the data on equipment performance and causes of its failure can be securely logged and transferred in case of accidents; blockchain technology could come as a great help in this regard.

\subsection{Safety}

While increased safety can also be translated in cost reductions, for instance, in terms of reduced insurance fees, we distinguish it as a separate category, because its value is often difficult to measure and different actors in the logistics ecosystem can benefit from it in various ways. As one interviewee put it, in maritime business 
segments like offshore or passenger transportation, safety is the aspect whose improvement is prioritized over such goals as direct cost savings, as it can be easily compromised. The extent to which the value can be monetized depends on the segment and particular business case. In case of passenger transportation in the Baltic Sea, for example, safety can be seen as the part of the brand value for ship operators. Offshore business and pilotage were mentioned as other examples of sectors where increased crew safety can be extremely valuable for ship operators.

There are also several aspects of how safety can be affected by autonomous operations. First, the safety of the vessel can be improved due to constant and advanced situational awareness brought by ship intelligence and reduction of the crew's fatigue by taking over routine tasks (Hogg and Ghosh 2016). Second, crew safety is improved due to the mere fact that seafarers are transferred to the shore and are not subject to operating vessels in harsh and dangerous conditions, or being held hostage during pirate attacks (Mooney 2015). Third, the transfer of operational decisions from the crew to the ship is often mentioned to bear the potential of reducing human error (Porathe 2013), particularly due to decreased fatigue (Nguyen et al. 2014), which has been claimed to cause $75-96 \%$ of accidents at sea (Rothblum et al. 2002). The latter point appears to be a controversial topic. Several interviewees mentioned that human error leading to disasters like collisions is a commonly used argument for promoting the benefits of safety of MASS. However, the presence of a crew has been crucial for detecting and avoiding such accidents as fires. Furthermore, in case of remotely operated ships, much of the safety risks are transferred to the SCC, necessitating constant monitoring and interpretations of data in order to ensure safe vessel operations (Hogg and Ghosh 2016).

\subsection{Earning potential}

Unmanned ships improve earning potential in several ways. The new opportunities in vessel design due to limited crew accommodation and life support systems, which were discussed earlier, create additional space for carrying cargo (Hogg and Ghosh 2016).

Increased ship intelligence due to digitalization, however, bears a more significant potential for creating new revenue streams by generating data that can be used to establish new business models. As an example, data on cargo condition during the voyage (such as position of cargo within containers or the temperature in a cargo hold), combined with other cargo-related data (such as weight, destination or ID of particular containers), as well as voyage information, can be the basis for providing real-time information on cargo movements, which can be valuable for the shippers and other actors interested in the transparency and visibility of supply chains. The data generated on an intelligent ship give rise to many more opportunities and interfaces, such as the ones related to IoT and automated supply chains, to create larger system value, which is discussed in the next section. 


\subsection{System value enabled by MASS}

As discussed above, unmanned vessels have the potential to create value by reducing crew-related costs, which has an effect on ship operating and investment costs. Ship intelligence can be seen as a necessary condition for MASS operations, enabling a whole set of other benefits related to increased situational awareness and improved decision-making during voyages. However, significant benefits lie beyond actual vessel operations, in the integration of MASS in the IoT (Sullivan et al. 2020; de la Peña Zarzuelo et al. 2020), where other smart infrastructures and equipment, such as ports with autonomous mooring and automated loading and unloading, and automated intermodal hubs, are also part of transparent and automatized supply chains.

As one interviewee explained, MASS supported by artificial intelligence (AI) have the potential to remove the inefficiencies in current logistics chains, thereby also reducing the environmental impact of cargo transportation. This stems from the combination of several 'ship intelligence' solutions, such as voyage optimization and optimal cargo loading, and digital innovations in other parts of the logistics chain, such as management of truck traffic in ports and multimodal logistics planning. The alignment of these optimization solutions can allow, for example, reduction of ships' waiting time in port and instead find optimal routes and speed profiles to deliver goods on time.

It is important to note that ships can be 'intelligent' without being fully unmanned and autonomous. This view is shared by some leading ship technology suppliers, such as ABB and Wärtsilä, who have been cautious regarding the concept of fully autonomous vessels, ${ }^{2}$ and have instead referred to "Smart Marine" 3 and "conditionally and periodically unmanned bridge." MASS are often seen as a future technology for naval and research applications, while "smart ships" are seen better fit for commercial shipping (Lloyd's Register 2015). However, the combination of unmanning vessels with increasing ship intelligence can create system value for supply and logistics chains by allowing vessels to be operated flexibly and in real time without accounting for crew on board. As an interviewee suggested, fully autonomous ships can enable not only 'digital corridors', but also digital trade, where fully unmanned ships can be treated as 'floating stocks' that can be traded in real time and be flexibly redirected to any port. Along similar lines, Kim et al. (2020) see future transportation as a "timely service that allows shippers and customers to instantaneously tailor dispatches and receive deliveries from this autonomous logistics transport chain". Furthermore, MASS can contribute to establishing new platforms, where digitalization can help leverage business opportunities and to monetize data pertaining to shipping operations (Wright 2020).

Thus, system value enabled by MASS is two-fold. On the one hand, autonomous shipping, integrated in the increasingly digitalized maritime transportation

\footnotetext{
${ }^{2}$ https://www.wartsila.com/twentyfour7/innovation/maritime-autonomy-a-bridge-too-far.

3 https://www.wartsila.com/marine/smartmarine/cases/case-smart-marine.

${ }^{4}$ https://new.abb.com/marine/media-center/press-releases-and-articles/articles-and-highlights/b0-aconditionally-and-periodically-unmanned-bridge.
} 
(Tsvetkova et al. 2021b), enables value creation through complementarities among ecosystem actors (Jacobides et al. 2018) such as port operators, freight forwarders and logistics operators. On the other hand, as more MASS are introduced in maritime logistics, it should be possible to achieve network effects (Katz and Shapiro 1985), where the value created by a fleet of MASS will be able to outperform conventional vessels on a new level. According to an interviewee, a fleet of many smallsize container MASS can deliver goods from origin to destination economically, replacing the hub-and-spoke networks that rely on mega-size container vessels and feeders. In both cases, system value of MASS has ramifications for supply and logistics chains, which are discussed below.

Finally, it is worthwhile mentioning the additional value that can be created by MASS, which is difficult to categorize according to the topics discussed above. First, the modal shift from road transport to MASS in short-sea shipping (Suárez-Alemán 2016) will bring benefits to society by reducing the environmental impacts of cargo transportation (Munim 2019). An interviewee explained that, to make ship power and the propulsion system more independent, it will be necessary to shift either to cleaner fuels or preferably to electric propulsion. The use of heavy fuel oil (HFO), for example, will be impossible on MASS (Kretschmann et al. 2017).

\section{Discussion}

\subsection{Changes in the structure of logistics business ecosystem due to the introduction of MASS}

There are benefits of unmanned vessels and of increased ship intelligence that can improve ship operations in 'as-is' logistics business ecosystems, such as reducing crew costs or increasing safety due to better situational awareness. These benefits provide incremental improvements compared with conventional ships, and have been extensively discussed by providers of autonomous capability on ships and other promoters of autonomous shipping, to establish the relatively higher value of MASS. With regard to such benefits, the analysis of value creation using an ecosystem perspective can provide answers to the question of which particular actors will be able to capture this value and, if this proves difficult, which changes in the structure of the ecosystem would be necessary. As one interviewee put it, it is possible that certain investments in ship intelligence will pay off even if business is done in the same way as today. However, to fully realize the value of MASS, it is necessary to go beyond the current structure of the logistics business ecosystem and see whether new business models are possible. For example, operation of a fleet of MASS is an opportunity for a new business model that can be employed not only by incumbent actors such as ship operators, but also by technology providers (Duru 2019). As we can conclude from the analysis above, system value can be created only if the business ecosystem is transformed and the business models of many actors change accordingly. However, it is not immediately apparent how value creation and capture will change in such a transformed ecosystem. In Table 4, we analyse for which actors in the logistics ecosystem MASS create value by exploring 


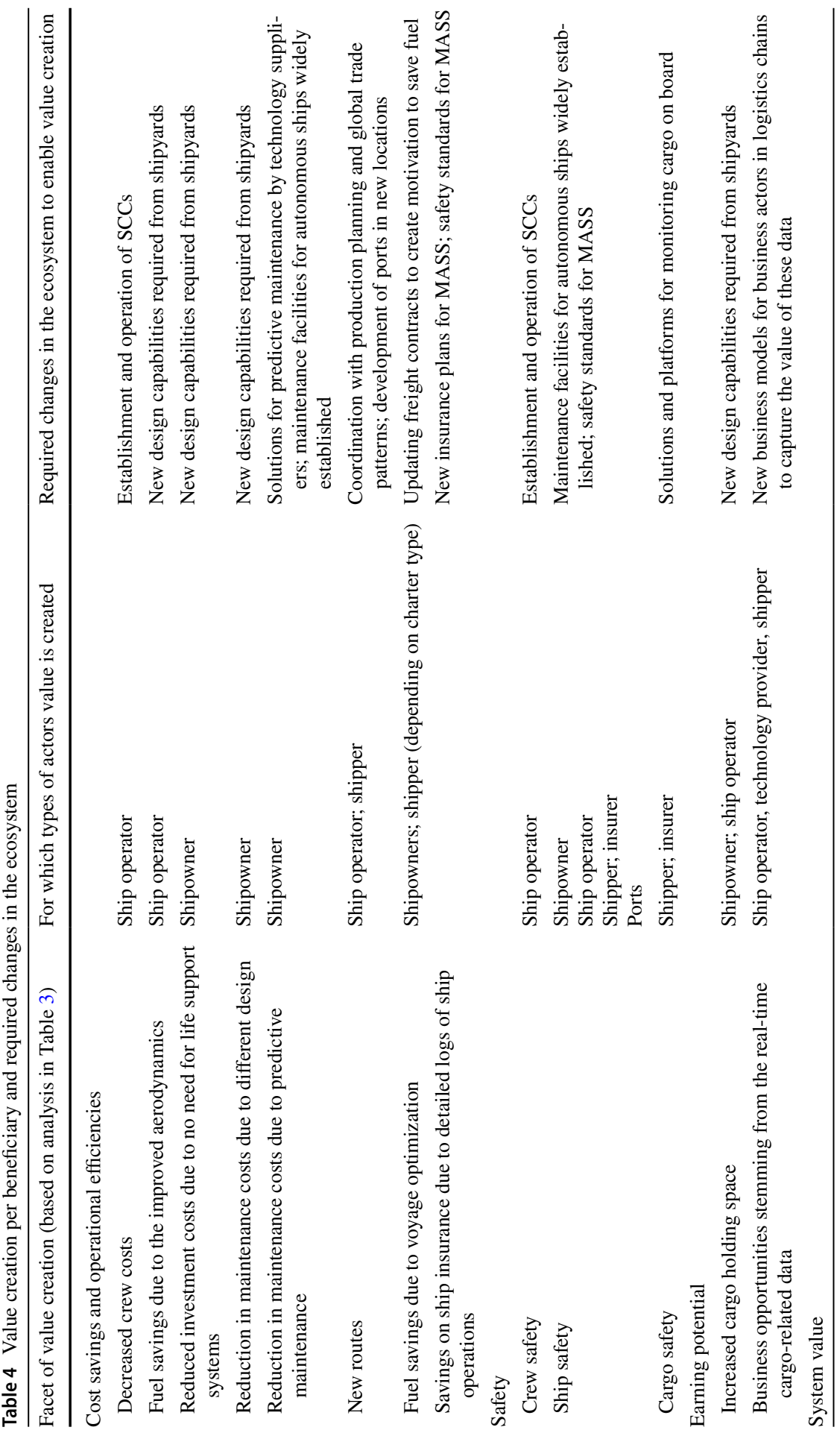




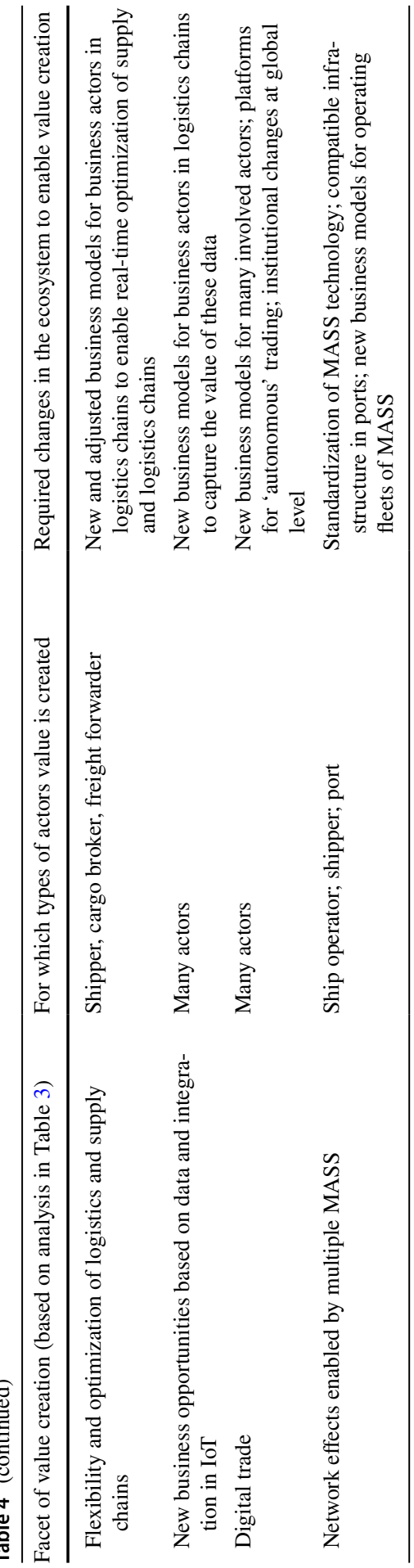

称。 
each facet of value creation discussed in the previous section and listed in Table 3 This analysis provides the understanding of the needs for ecosystem redesign and is therefore instrumental in predicting how supply and logistics chains will change due to the wide introduction of MASS.

While commonly mentioned benefits of MASS such as increased safety and cost reductions mainly concern shipowners and ship operators, system value would be created mostly for the ultimate logistics customer: the shipper (and trade by and large). The challenge here relates to the fact that shipbuilding can be seen as a distinct sector where the shipowner is the ultimate customer (Gustafsson et al. 2015). In cases where the shipowner is also operating the ship, the benefits that concern vessel operations can also be captured by this actor. However, in the case of MASS, the providers of autonomous capability can create value that spans across the logistics chain. The challenges arise in motivating higher investment costs in MASS if it is unclear how shipowners can benefit, or whether it will be other actors in the ecosystem who will capture the value from intelligent and unmanned ships.

It has been argued that the successful implementation of MASS in maritime logistics will directly depend on their potential to increase the profitability of shipowners and operators (Kretschmann et al. 2017). In this perspective, some value is transferred to shippers through potentially lower freight rates and safer cargo transportation. However, the value of transparency, the flexibility in logistics and supply chain management, and the development of IoT will be created for actors that use MASS for transporting their cargo and can only be enabled if the business ecosystem is transformed. Some actors need to take additional roles and develop necessary capabilities (e.g. related to the remote operation of MASS or new ways to organize their maintenance), while others will lose their position in the ecosystem as their activities will become obsolete. The principles of how value is created in the ecosystem need to change. The winners are likely to be those actors that manage to orchestrate and align the ecosystem in such a way that more value can be created.

\subsection{Capturing the value of MASS: the changing roles of technology providers, shipyards, shipowners and ship operators}

As Kim et al. (2020) note, the introduction of MASS will clearly have an impact on ship design, shipbuilding, and port infrastructure, including services and interfaces. One particular question concerns the division of roles between incumbent actors such as shipowners and operators and the 'digital newcomers,' i.e. the providers of autonomous capability for ships. In a traditional setting, technology providers act as suppliers to shipyards, whose customers are shipowners. It has been noted before that, in this linear and fragmented supply chain, the technology providers are not always capable of delivering the value that their systems are capable of creating (Gustafsson et al. 2015). The role of the shipyard as a system integrator might be challenged by the potential of technology providers (related to ship intelligence), as the latter become indispensable in data ecosystem formation. While shipbuilding has focused on design for reliability and maintainability, the increasing incorporation of data management elements needs to be reflected in engineering vessels 
and requires novel capabilities (Hogg and Ghosh 2016). In particular, the need to ensure vessel connectivity at sea and the generation and use of new types of data (e.g. on cargo condition, equipment condition and the surroundings of the vessel) will require ensuring cybersecurity and building new interfaces between ship systems (such as connecting the situational awareness with the navigational system via a decision-making algorithm to avoid collisions).

Further, a commonly discussed challenge is the question of liability in case of accidents and damages that involve MASS. It is still unclear whether it is the shipowner, the shipyard or the provider of autonomous capability who will be held liable, and which liability regimes will apply. In this sense, ships differ significantly from cars, where the manufacturer controls the supply chain and the technology development much more intensively than shipyards. There is an urgent need to establish reasonable criteria and scope on responsibility between shipowners, technology providers and shipyards, including an appropriate security structure for insurance coverage (Kim et al. 2020).

MASS will naturally change the way ships are operated, thereby questioning the established role of the ship operator. Remote operations will require establishing SCCs, which need the resources and capabilities both of technology providers and incumbent ship operators. It is still unclear whose responsibility it is to develop and maintain SCCs - the shipbuilder or the technology supplier (Ghaderi 2020). As one interviewee argued, there will be ship operating companies that will not want to build and operate their own SCCs, thereby turning to technology providers for a service to operate MASS from their SCCs.

This gives rise to new business models (and new types of actors in the ecosystem) that would operate MASS. Masterly is an interesting example of such a new business actor that offers a complete value chain for AS, from design and development to control systems, logistics services and vessel operations (Wilhelmsen 2018). In the future, it is possible that MASS manufacturers would offer shared MASS alongside ownership offers (Munim 2019). While such a ship-as-a-service (SaaS) business model is not new (various chartering arrangements being examples of how users of ships do not need to actually own them in order to manage the transport of their cargo), in the case of MASS, the roles of shipowner, ship operator and SaaS providers will be rearranged (Duru 2019). Moreover, as Munim (2019) proposes, the business models of these actors will differ depending on whether incumbent or new firms take lead in this part of the ecosystem. The tension between the incumbent and emerging logistics business ecosystems is further aggravated by the opinions that, although technology providers are clearly the drivers of ecosystem transition and propagators of MASS, they do not understand the specifics of the maritime industry to a necessary extent (Meadow et al. 2018; Wright 2020).

Another important aspect that stems from the analysis presented in Table 4 is that the value of MASS, especially when it comes to system value, can be created for the ultimate users of MASS, i.e., shippers. While operational efficiencies brought by MASS can be captured by the shipowner and operator in the incumbent ecosystem or if the structure of the business ecosystem changes in terms of ship ownership and operation as discussed above, it is far more challenging to match the value creation potential for shippers, as they are not investing in vessels. Vertical integration has 
been proposed as a possible scenario for overcoming this challenge, and companies like Amazon have been mentioned as potential first movers in deploying MASS, as they are both capable of capturing the system value created by MASS owing to the control over the end-to-end logistics chains and have the financial means to invest in this technology and the required complementary infrastructure (e.g. in ports). Along similar lines, Yara Birkeland has been mentioned by an interviewee as an example of embedding a MASS as part of the supply chain controlled end-to-end by one company. As Kretschmann et al. (2017) note, Yara's motivation to invest in a MASS is probably the savings achieved through enhanced management and optimization of supply chains by engaging the ships for transportation of large quantities of cargo.

\subsection{Complementarity in actor activities and investments to enable value creation by MASS}

To enable system value creation, there is a need for certain complementary activities and roles to be established or revised. For example, there is a clear need for ports to adjust their activities and infrastructure to accommodate MASS and allow for creating value through seamless, automated operations in ports. As one interviewee mentioned, a number of activities need to be automated, such as ship-toshore communication and docking, and port systems need to be compatible with MASS. There is also a need for interoperability and standardization of the different systems on MASS for them to be able to enter different ports. At the same time, ports will be able to capture some of the value created by MASS through higher port dues, job creation and increased short-sea shipping activity (Ghaderi 2020). Another challenge related to ports' ability to host MASS lies in the different operational profiles of such vessels, as they will probably spend more time in port to carry out tasks such as maintenance that would have otherwise been performed by the crew during the voyage. This will lead to the deterioration of value created to port operators, who aim for higher throughput of vessels (Ghaderi 2020).

Technological complementarities that need to be developed in the emerging ecosystem include ship propulsion that would not rely on internal combustion technology, which is heavily dependent on crew presence on board (Wright 2020) and automation. Also, implementation of MASS, especially in ocean shipping, requires the development of sufficient and reliable connectivity. Finally, there will be significant implications for electric grids as more and more electric MASS will need to charge in ports. Technologies and services for fast-charging of the battery and back-up batteries will be required to enable efficient MASS operations (Munim 2019). It is as yet unclear which ecosystem actors will take the lead in developing and maintaining this infrastructure and how they will be able to monetize the complementary value they create. Finally, the role of the ultimate users of the vessels - the shippers - will probably change as logistics chains that include MASS become automated and more transparent. In essence, this should give more power to the shippers and open the 'black box' of sea logistics. 


\section{Conclusions}

The expected benefits of MASS include increased safety, reduced costs and increased earning potential due to operational efficiencies and reduction in vessel manning. However, autonomous shipping bears a greater potential than just replacing humans with machines. Rather, MASS can play a role in transforming logistics and supply chains. The value creation potential of MASS depends on the degree to which it disrupts logistics, which correlates to the degree of autonomy at which MASS can operate. The aim of this study was to clarify the mechanisms of value creation enabled by MASS and outline the requirements for changing the value creation and capture structure of logistics chains by applying an ecosystem perspective to them.

We distinguish between two main sources of value creation by MASS - unmanned vessels and ship intelligence - because they have different implications on which actors can capture the value and in which way. Certain categories of value, such as improved safety and cost reductions, can be the basis for comparing MASS with conventional ships in order to elicit relative improvements. This is important to understand, as the first generation of MASS might need to compete with conventional ships directly (Kretschmann et al. 2017). However, a more significant value potential lies in system value which is enabled through network effects and through establishing complementarities in the emerging ecosystem.

Major changes concern the shifting roles of the providers of autonomous capabilities, shipyards, shipowners and operators and their effect on settling the new structure of the logistics business ecosystem. Another consideration is the need for complementary activities, such as those undertaken by ports and SCCs, and new business models enabled by, among other factors, increased transparency and predictability. Meanwhile, there will be a long struggle to find niches where MASS can indeed offer competitive advancement compared with conventional ships. Another route would be constructing the digital maritime ecosystem (Urciuoli and Hintsa 2020) for integrating MASS into the IoT to hence enable the Industry 4.0 in the maritime context or the so-called Maritime 4.0 (Sullivan et al. 2020; de la Peña Zarzuelo et al. 2020). For that, the focus needs be shifted to ship intelligence, which is easier to be implemented than the unmanning of vessels.

Our research has been a probe in new terrain. The ecosystem view we have advocated seems to be relevant, and further research should attempt more fine-grained analyses of, for example, specific shipping segments or how value creation through MASS differs for different levels of autonomy and onboard manning (Fig. 1). It is likely that for some segments ship intelligence will be the main value driver, whereas for others it may be the reduction or removal of crew.

Funding Open access funding provided by Abo Akademi University (ABO). We acknowledge the funding provided by Academy of Finland, grant number 301843 (The Sea).

Open Access This article is licensed under a Creative Commons Attribution 4.0 International License, which permits use, sharing, adaptation, distribution and reproduction in any medium or format, as long as you give appropriate credit to the original author(s) and the source, provide a link to the Creative 
Commons licence, and indicate if changes were made. The images or other third party material in this article are included in the article's Creative Commons licence, unless indicated otherwise in a credit line to the material. If material is not included in the article's Creative Commons licence and your intended use is not permitted by statutory regulation or exceeds the permitted use, you will need to obtain permission directly from the copyright holder. To view a copy of this licence, visit http://creativecommons.org/ licenses/by/4.0/.

\section{References}

Adner, Ron. 2017. Ecosystem as structure: an actionable construct for strategy. Journal of Management 43 (1): 39-58. https://doi.org/10.1177/0149206316678451.

Adner, Ron, and Rahul Kapoor. 2010. Value creation in innovation ecosystems: how the structure of technological interdependence affects firm performance in new technology generations. Strategic Management Journal 31 (3): 306-333. https://doi.org/10.1002/smj.821.

Amit, Raphael, and Christoph Zott. 2001. Value creation in e-business. Strategic Management Journal 22 (6-7): 493-520. https://doi.org/10.1002/smj.187.

Baldauf, Michael, Momoko Kitada, Raza Mehdi, and Dimitrios Dalaklis. 2018. E-navigation, digitalization and unmanned ships: challenges for future maritime education and training. In INTED2018 Proceedings, 1:9525-30. IATED. https://doi.org/10.21125/inted.2018.2374.

Björkroth, P. 2020. MacGyvers or human drones - what will future seafarers be like? (Agnieszka Hynnekleiv Part 1). Maritime Podcast. https://www.novia.fi/novialia/poddar/martime-podcast/peter mbjorkroth.

Cohen, Louis, Lawrence Manion, and Keith Morrison. 2017. Research Methods in Education, 8th ed. London: Routledge.

Denktas-Sakar, Gul, and Cimen Karatas-Cetin. 2012. Port sustainability and stakeholder management in supply chains: a framework on resource dependence theory. The Asian Journal of Shipping and Logistics 28 (3): 301-319. https://doi.org/10.1016/J.AJSL.2013.01.002.

Duru, Okan. 2019. The Future Shipping Company: Autonomous Shipping Fleet Operators. The Maritime Executive. October 12. https://www.maritime-executive.com/editorials/the-future-shipping-compa ny-autonomous-shipping-fleet-operators.

Eriksson, Kent, Kim Wikström, Magnus Hellström, and Raymond E. Levitt. 2019. Projects in the business ecosystem: the case of short sea shipping and logistics. Project Management Journal 50 (2): 195-209. https://doi.org/10.1177/8756972818820191.

Ghaderi, Hadi. 2019. Autonomous technologies in short sea shipping: trends, feasibility and implications. Transport Reviews 39 (1): 152-173. https://doi.org/10.1080/01441647.2018.1502834.

Ghaderi, Hadi. 2020. Wider implications of autonomous vessels for the maritime industry: mapping the unprecedented challenges. Advances in Transport Policy and Planning 5: 263-289. https://doi.org/ 10.1016/bs.atpp.2020.05.002.

Gulati, Ranjay, Phanish Puranam, and Michael Tushman. 2012. Meta-organization design: rethinking design in interorganizational and community contexts. Strategic Management Journal 33 (6): 571586. https://doi.org/10.1002/smj.1975.

Gustafsson, Magnus, Anastasia Tsvetkova, Maria Ivanova-Gongne, Anu Keltaniemi, Tomi Nokelainen, and Víctor Sifontes. Herrera. 2015. Positioning Report. Analysis of the Current Shipping Industry Structure and a Vision for a Renewed Shipping Industry Ecosystem. Turku: Abo Akademi University.

Heilig, Leonard, and Stefan Voß. 2017. Status quo and innovative approaches for maritime logistics in the age of digitalization: a guest editors' introduction. Information Technology and Management 18 (3): 175-177. https://doi.org/10.1007/s10799-017-0282-z.

Hellström, Magnus, Anastasia Tsvetkova, Magnus Gustafsson, and Kim Wikström. 2015. Collaboration mechanisms for business models in distributed energy ecosystems. Journal of Cleaner Production. https://doi.org/10.1016/j.jclepro.2015.04.128.

Hogg, Trudi, and Samrat Ghosh. 2016. Autonomous merchant vessels: examination of factors that impact the effective implementation of unmanned ships. Australian Journal of Maritime \&amp; Ocean Affairs 8 (3): 206-222. https://doi.org/10.1080/18366503.2016.1229244. 
IMO. 2018. "IMO Takes First Steps to Address Autonomous Ships. http://www.imo.org/en/MediaCentre/PressBriefings/Pages/08-MSC-99-MASS-scoping.aspx\#: :text=For\%20the\%20purpose \%20of\% 20the,operate $\% 20$ independently $\% 20$ of $\% 20$ human $\% 20$ interaction.\&text $=$ Fully $\% 20$ autonomous $\%$ 20ship\%3A\%20The\%20operating,and\%20determine\%20actions\%20by\%20itself.

Inkinen, Tommi, Reima Helminen, and Janne Saarikoski. 2019. Port digitalization with open data: challenges, opportunities, and integrations. Journal of Open Innovation: Technology, Market, and Complexity 5 (2): 30. https://doi.org/10.3390/joitmc5020030.

Jacobides, Michael G., Carmelo Cennamo, and Annabelle Gawer. 2018. Towards a theory of ecosystems. Strategic Management Journal 39 (8): 2255-2276. https://doi.org/10.1002/smj.2904.

Katz, Michael L., and Carl Shapiro. 1985. Network externalities, competition, and compatibility. American Economic Review. https://doi.org/10.2307/1814809.

Kim, Mingyu, Tae-Hwan. Joung, Byongug Jeong, and Han-Seon. Park. 2020. Autonomous shipping and its impact on regulations, technologies, and industries. Journal of International Maritime Safety, Environmental Affairs, and Shipping. https://doi.org/10.1080/25725084.2020.1779427.

Kretschmann, Lutz, Hans Christoph Burmeister, and Carlos Jahn. 2017. Analyzing the economic benefit of unmanned autonomous ships: an exploratory cost-comparison between an autonomous and a conventional bulk carrier. Research in Transportation Business and Management 25: 76-86. https://doi.org/10.1016/j.rtbm.2017.06.002.

Lambert, Nick, Jonathan Turner, and Andy Hamflett. 2019. Technology and the Blue Economy: From Autonomous Shipping to Big Data. London: Kogan Page, Limited.

Lam, Jasmine Siu Lee., Adolf K.Y.. Ng, and Xiaowen Fu. 2013. Stakeholder management for establishing sustainable regional port governance. Research in Transportation Business and Management 8: 30-38.

la Peña Zarzuelo, Ignacio de, María Jesús Freire Soeane, and Beatriz López Bermúdez. 2020. Industry 40 in the port and maritime industry: a literature review. Journal of Industrial Information Integration 20: 100173. https://doi.org/10.1016/j.jii.2020.100173.

Liu, Gordon, Lukman Aroean, and Wai Wai Ko. 2019. A business ecosystem perspective of supply chain justice practices: a study of a marina resort supply chain ecosystem in Indonesia. International Journal of Operations and Production Management 39 (9-10): 1122-1143. https://doi. org/10.1108/IJOPM-09-2018-0578.

Lloyd's List. 2017. Top 10 Technology Leaders 2017. https://lloydslist.maritimeintelligence.informa. com/LL1120201/Top-10-technology-leaders-2017.

Lloyd's Register, QinetiQ and University of Southampton. 2015. Global Marine Technology Trends 2030.

Mayring, Philipp. 2004. Qualitative Content Analysis. In A Companion to Qualitative Research, ed. Uwe Flick, Ernst von Kardorff, and Ines Steinke, 266-269. London: SAGE.

Meadow G., D. Ridgwell, and D. Kelly. 2018. Autonomous Shipping: Putting the Human Back in the Headlines. Singapore.

Mooney, Turloch. 2015. Study Finds Autonomous Ships Unlikely within next Decade. The Journal of Commerce Online. December 1. https://www.joc.com/maritime-news/ships-shipbuilding/auton omous-ships-unlikely-next-decade_20151201.html.

Moore, James F. 1996. The Death of Competition: Leadership \&amp; Strategy in the Age of Business Ecosystems. New York: Harper Business.

Munim, Ziaul Haque. 2019. Autonomous ships: a review, innovative applications and future maritime business models. Supply Chain Forum: An International Journal 20 (4): 266-279. https://doi. org/10.1080/16258312.2019.1631714.

Munim, Ziaul Haque, Rana Saha, Halvor Schøyen, Adolf K. Y. Ng, and Theo E. Notteboom. 2021. Autonomous ships for container shipping in the Arctic routes. Journal of Marine Science and Technology. https://doi.org/10.1007/S00773-021-00836-8.

Nguyen, Trong Thanh, Hadi Ghaderi, Livingstone Divine Caesar, and Stephen Cahoon. 2014. Current challenges in the recruitment and retention of seafarers: an industry perspective from Vietnam. Asian Journal of Shipping and Logistics 30 (2): 217-242. https://doi.org/10.1016/j.ajs1.2014.09. 005.

Osterwalder, Alexander, and Yves Pigneur. 2010. Business Model Generation: A Handbook for Visionaries, Game Changers, and Challengers. New York: Wiley.

Porathe, T. 2013. MUNIN Deliverable 7.1: Error and Human Intervention Report in the Context of Autonomous Vessels. MUNIN Report. 
Porter, Michael E., and James E. Heppelmann. 2015. How smart, connected products are transforming companies. Harvard Business Review 93 (10): 96-114.

Ringbom, Henrik. 2019. Regulating autonomous ships-concepts, challenges and precedents. Ocean Development \&amp; International Law 50 (2-3): 141-169. https://doi.org/10.1080/00908320. 2019.1582593.

Rothblum, A.M., D. Wheal, S. Withington, S.A. Shappell, D.A. Wiegmann, W. Boehm, and M. Chaderjian. 2002. Human Factors in Incident Investigation and Analysis. In Proceedings of the 2nd International Workshop on Human Factors in Offshore Operations (HFW2002). Houston, USA.

Snihur, Yuliya, Llewellyn D. W. Thomas, and Robert A. Burgelman. 2018. An ecosystem-level process model of business model disruption: the disruptor's gambit. Journal of Management Studies 55 (7): 1278-1316. https://doi.org/10.1111/JOMS.12343.

Suárez-Alemán, Ancor. 2016. Short sea shipping in today's Europe: a critical review of maritime transport policy. Maritime Economics and Logistics 18 (3): 331-351. https://doi.org/10.1057/ mel.2015.10.

Sullivan, Brendan P., Shantanoo Desai, Jordi Sole, Monica Rossi, Lucia Ramundo, and Sergio Terzi. 2020. Maritime 4.0 - opportunities in digitalization and advanced manufacturing for vessel development. Procedia Manufacturing 42: 246-253. https://doi.org/10.1016/j.promfg.2020.02.078.

Talmar, Madis, Bob Walrave, Ksenia S. Podoynitsyna, Jan Holmström, A. Georges, and L. Romme. 2018. Mapping, analyzing and designing innovation ecosystems: the ecosystem pie model. Long Range Planning 53 (4): 101850. https://doi.org/10.1016/j.lrp.2018.09.002.

Teece, David J. 2010. Business models, business strategy and innovation. Long Range Planning 43 (2-3): 172-194. https://doi.org/10.1016/j.1rp.2009.07.003.

Tsvetkova, Anastasia, Magnus Gustafsson, and Kim Wikström. 2021a. Digitalising maritime transport: digital innovation as a catalyser of sustainable transformation. In A Modern Guide to the Digitalization of Infrastructure, ed. Juan Montero and Mattias Finger. Cheltenham: Edward Elgar Publishing.

Tsvetkova, Anastasia, Magnus Hellström, and Henrik Ringbom. 2021b. Creating value through productservice-software systems in institutionalized ecosystems - The case of autonomous ships. Industrial Marketing Management 99: 16-27. https://doi.org/10.1016/j.indmarman.2021.09.007

Tsvetkova, Anastasia, Tomi Nokelainen, Magnus Gustafsson, and Kent Eriksson. 2017. A framework for ecosystemic strategizing and change. In Practices for Network Management: In Search of Collaborative Advantage, ed. Jukka Vesalainen, Katri Valkokari, and Magnus Hellström, 275-301. Cham: Springer. https://doi.org/10.1007/978-3-319-49649-8_20.

Urciuoli, Luca, and Juha Hintsa. 2020. Can digital ecosystems mitigate risks in sea transport operations? Estimating benefits for supply chain stakeholders. Maritime Economics and Logistics. https://doi. org/10.1057/s41278-020-00163-6.

Viswanadham, N., and A. Samvedi. 2013. Supplier selection based on supply chain ecosystem, performance and risk criteria. International Journal of Production Research 51 (21): 6484-6498. https:// doi.org/10.1080/00207543.2013.825056.

Wilhelmsen. 2018. Wilhelmsen and KONGSBERG Establish World's First Autonomous Shipping Company. Press Release. April 3. https://www.wilhelmsen.com/media-news-and-events/press-releases/ 2018/wilhelmsen-and-kongsberg-establish-worlds-first-autonomous-shipping-company/.

Wright, R Glenn. 2020. Unmanned and Autonomous Ships. Unmanned and Autonomous Ships. London: Routledge. https://doi.org/10.1201/9780429450655.

Zott, Christoph, and Raphael Amit. 2010. Business model design: an activity system perspective. Long Range Planning 43 (2-3): 216-226. https://doi.org/10.1016/j.lrp.2009.07.004.

Zott, Christoph, Raphael Amit, and Lorenzo Massa. 2011. The business model: recent developments and future research. Journal of Management 37 (4): 1019-1042. https://doi.org/10.1177/0149206311 406265 .

Publisher's Note Springer Nature remains neutral with regard to jurisdictional claims in published maps and institutional affiliations. 